\title{
Symptomatic hypopituitarism revealing a primary empty sella turcica
}

\author{
B. VELKENIERS* \\ M.D. \\ D. DESIR* \\ M.D. \\ D. MANicourt $\dagger$ \\ M.D. \\ F. Chanoine $\dagger$ \\ M.D. \\ M. DUPONT**
M.D. \\ G. CoPINSCHI* \\ M.D., Ph.D. \\ *Department of Endocrinology, and **Service of Radiology, University Hospital St Pierre, Brussels, and \\ $\dagger$ Department of Medicine, Tournai Hospital, University of Brussels, Brussels
}

\begin{abstract}
Summary
A 64-year-old nulliparous woman presented with clinical signs of thyroid and adrenocortical insufficiency. Subsequent hormonal investigations demonstrated a failure of all anterior pituitary functions. Pneumotomo-encephalography revealed a large arachnoid herniation, leading to the diagnosis of primary empty sella turcica syndrome with secondary panhypopituitarism. This unusual observation emphasizes the necessity of ruling out an empty sella turcica syndrome in patients with pituitary insufficiency.
\end{abstract}

\section{Introduction}

Primary empty sella turcica syndrome is a frequent cause of enlarged sella turcica (Weisberg, Zimmerman and Frantz, 1976), although in a few cases it has also been documented in sellas of normal size (Bergland, Ray and Torack, 1968). In some subjects, the syndrome remains asymptomatic for prolonged periods and the diagnosis is only made at postmortem or following routine X-rays (Neelon, Goree and Lebovitz, 1973). When clinical signs are present, headache is the most frequent initial symptom (Berke, Buxton and Kokmen, 1975; Jordan, Kendall and Kerber, 1977). Clinical signs of endocrine disturbances are uncommon (Brisman, Hughes and Holub, 1972; Faglia et al., 1973). The present article reports an unusual case of empty sella turcica, with clinical symptoms of panhypopituitarism.

\section{Case report}

A 64-year-old woman was referred to the hospital because of muscular cramps, intense asthenia, anorexia, nausea, postprandial vomiting and severe constipation. These symptoms developed one month before admission. This nulliparous patient had

Reprint requests: G. Copinschi, M.D., Laboratory of Experimental Medicine, University of Brussels, rue Evers 2, B-1000 Brussels, Belgium. normal menses until the age of 44 years. She had had a mixed parotid tumour, treated by surgery and radiotherapy 20 years before, and had suffered minor cranial trauma without loss of consciousness 5 years before. Headaches were notes subsequently but were never investigated.

Physical examination revealed an apyretic obese woman $(74 \mathrm{~kg}, 164 \mathrm{~cm})$. Her skin was dry and pale, her hair was brittle, sparse and coarse. Pubic and axillary hair was scarce. The relaxation phase of deep tendon reflexes was prolonged. Blood pressure was $100 / 60 \mathrm{mmHg}$ in supine and standing positions. Heart rate was $72 / \mathrm{min}$. The rest of the examination was normal.

Laboratory investigations are summarized in Table 1 and as follows: thyroxine $37.4 \mathrm{nmol} / \mathrm{l}$; triiodothyronine $0.7 \mathrm{mmol} / \mathrm{l}$; sodium $115 \mathrm{mmol} / 1$; potassium $3.8 \mathrm{mmol} / 1$; chloride $96 \mathrm{mmol} / 1$; haematocrit $29 \%$. Basal plasma concentrations of thyroid hormones and of cortisol, and urinary excretion of 17-hydroxysteroids (17-OHCS) and 17-ketosteroids (17-KS) were sub-normal. Plasma gonadotrophins were low, especially if compared with post-menopausal values. Plasma thyroid stimulating hormone (TSH) was undetectable. Hyponatraemia and normochromic microcytic anaemia were present. Fasting plasma glucose concentrations were within normal limits.

Despite a fall of the plasma glucose concentrations to $1.5 \mathrm{mmol} / 1$ (induced by only $0.05 \mathrm{u}$. $/ \mathrm{kg}$ body weight of insulin), no increase of plasma cortisol, growth hormone or prolactin was observed following insulin-induced hypoglycaemia. Metyrapone elicited no significant steroid response. In contrast, a marked cortisol increase occurred after intravenous injection of tetracosactrin. Plasma values of thyrotrophin, gonadotrophins and prolactin remained unchanged during a combined LHRH-TRH stimulation test.

Visual fields and eye fundus were normal, standard $\mathrm{X}$-rays of the skull and sellar tomography disclosed 
TABLE 1. Stimulation tests

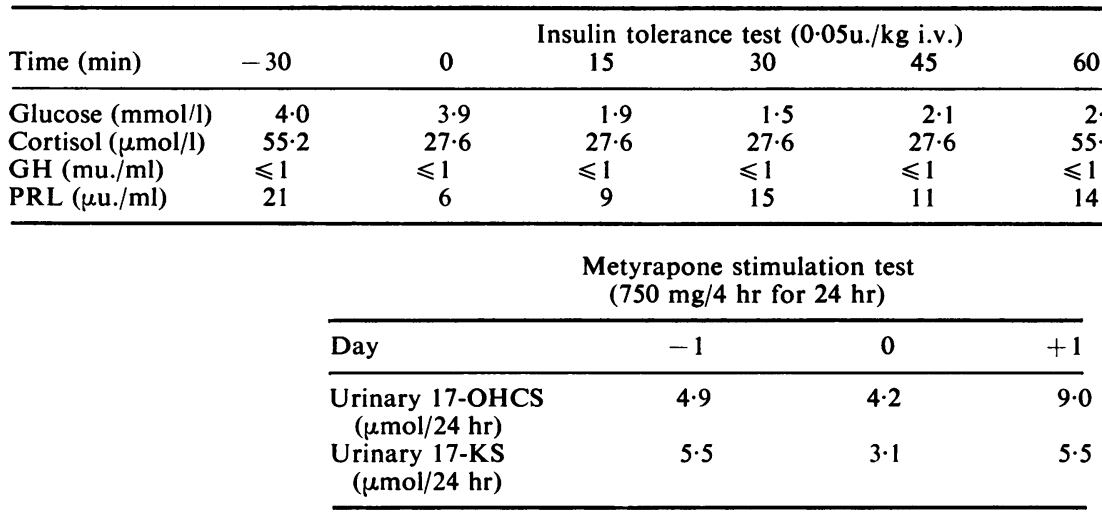

Tetracosactrin stimulation test $(0 \cdot 25 \mathrm{mg}$ i.v. $)$

\begin{tabular}{lccccc}
\hline Time $(\mathrm{min})$ & 0 & 30 & 60 & 90 & 180 \\
\hline Cortisol $(\mu \mathrm{mol} / \mathrm{l})$ & 82.8 & $331 \cdot 2$ & 276 & $220 \cdot 8$ & $165 \cdot 6$ \\
\hline
\end{tabular}

Gonadotrophin releasing $(\mathrm{LHRH})$ and thyrotrophin releasing hormone (TRH) stimulation test (200 mu. and $100 \mathrm{mu}$. i.v.)

\begin{tabular}{|c|c|c|c|c|c|c|}
\hline Time (min) & -30 & 0 & 15 & 30 & 60 & 120 \\
\hline TSH ( $\mu \mathrm{u} . / \mathrm{ml})$ & $\leqslant 1 \cdot 1$ & $\leqslant 1 \cdot 1$ & $\leqslant 1 \cdot 1$ & $\leqslant 1 \cdot 1$ & $\leqslant 1 \cdot 1$ & $\leqslant 1 \cdot 1$ \\
\hline PRL $(\mu \mathrm{u} . / \mathrm{ml})$ & 37 & 24 & 13 & - & 36 & 38 \\
\hline LH (mu./ml) & $1 \cdot 2$ & $1 \cdot 0$ & 0.8 & $1 \cdot 2$ & $1 \cdot 8$ & $1 \cdot 4$ \\
\hline FSH (mu./ml) & $2 \cdot 0$ & 3.0 & $2 \cdot 7$ & $2 \cdot 7$ & $3 \cdot 0$ & $4 \cdot 1$ \\
\hline
\end{tabular}

TSH = thyroid stimulating hormone; PRL = prolactin LH = luteinizing hormone; FSH = follicle stimulating hormoñe

moderate enlargement and ballooning of the sella turcica.

These findings were consistent with a diagnosis of panhypopituitarism secondary to a pituitary tumour. Considering the patient's clinical state, corticoid and thyroid replacement therapy was immediately started, before completing further investigations. Therefore, a pneumotomo-encephalographic examination was performed only several months later. It allowed visualization of a large arachnoid herniation, which filled up the sella turcica with air, leaving a small pituitary residue in the postero-inferior region, without any sign suggesting a pituitary tumour (Fig. 1). Thus, the final diagnosis was primary empty sella turcica syndrome with secondary panhypopituitarism. Hormonal therapy at present consists of cortisone acetate $(25 \mathrm{mg}$ in the morning, $12.5 \mathrm{mg}$ in the evening) and of 1-thyroxine ( $0.15 \mathrm{mg}$ daily).

\section{Discussion}

The empty sella turcica syndrome accounts for about $25 \%$ of enlarged sellas (Weisberg et al., 1976). Most patients are obese (75-95\%), hypertensive (29-58\%) females (87-91\%) (Neelon et al., 1973; Jordan et al., 1977). The syndrome is most often diagnosed in patients aged $40-55$ years. The clinica蒫 symptoms include headache $(45-80 \%)$, rhinorrhoea (0-8\%) (Weisberg et al., 1976; Berke et al., 1975), but $38 \%$ are asymptomatic. A clinical picture of pituitary insufficiency is exceptional, although ab-0. normal hormonal status may be revealed by laboratory studies (Weisberg et al., 1976; Brisman $e \underline{\mathrm{B}}$. al., 1972).

In a few cases, hormonal disturbances could be related to the association of empty sella turcica withô the infarction of a hormonally active pituitary ade- $₹$ noma revealed at pneumoencephalography ( 5 cases $ᄋ$ of prolactinomas (Jordan et al., 1977; Schaison and Metzger, 1969; Bar, Mazzaferri and Malarkey, 1975;을 Bryner and Greenblatt, 1977), 2 cases of Cushing's $N$ disease (Ganguly et al., 1976; Mortara and Norrell,-, 1970), 2 cases of acromegaly (Neelon et al., 1973; N Molitch et al., 1977). Diabetes insipidus associated స్ట with primary empty sella syndrome was reportedo in 4 cases (Schaison and Metzger, 1969; Cupps ando Wolff, 1978; Marisson and Pimstone, 1973). Two cases with gonadotropic insufficiency (Neelon et al., $\stackrel{\oplus}{+}$ 1973; Bernasconi, Giovanelli and Papo, 1972) were 7 also described. Five patients were found to have pan-우 hypopituitarism; 2 of them presented with clinical $\stackrel{\mathbb{\Omega}}{\Omega}$ 


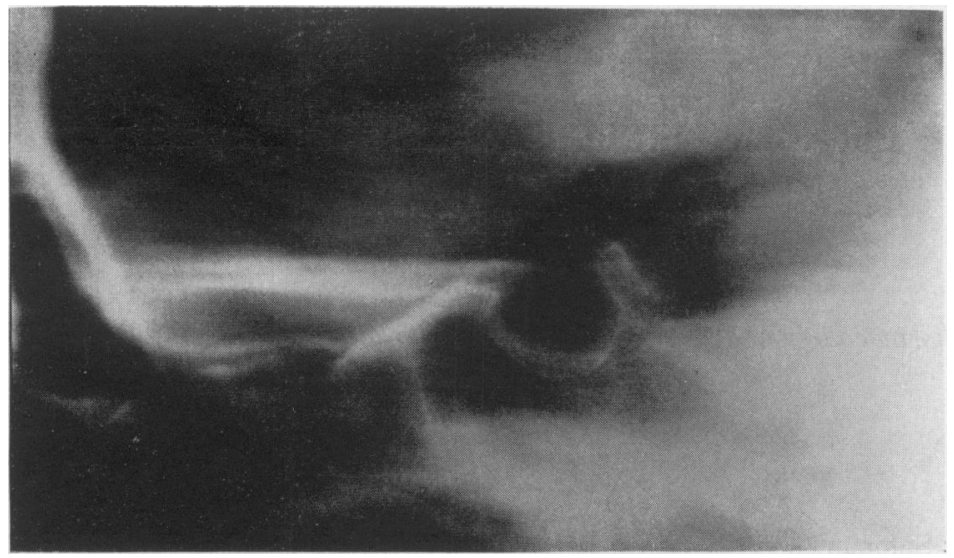

FIG. 1. Sagittal tomogram of sella turcica during pneumo-encephalography.

myxoedema (Neelon et al., 1973; Cupps and Woolf, 1978), one patient was admitted with generalized weakness and loss of appetite (Mortara and Norrell, 1970), and two subjects had a picture of panhypopituitarism (without further details), secondary to meningo-encephalitis and cranial trauma respectively (Schaison and Metzger, 1969).

The patient described in the present paper was, as usual, an obese female, but the clinical picture was quite unusual. Although headache was present, the clinical status was dominated by signs of thyroid and adrenocortical insufficiency. Because of the age of the patient, clinical signs of possible gonadotropic and somatotropic insufficiency were not observable. Subsequent hormonal investigations demonstrated a failure of all anterior pituitary functions. Despite the absence of clinical, biological and radiological signs of pituitary tumour, the hypothesis of an association of empty sella turcica with infarction of a pituitary adenoma could not be absolutely ruled out.

This cause emphasizes the need to rule out an empty sella turcica syndrome in all cases presenting with a pituitary insufficiency, a sellar enlargement, or both.

\section{Acknowledgments}

This work was supported in part by a grant from the Belgian Fonds de la Recherche Scientifique Médicale.

\section{References}

Bar, R.S., Mazzaferri, E.L. \& Malarkey, W.B. (1975) Primary empty sella, galactorrhea, hyperprolactinemia, and renal tubular acidosis. American Journal of Medicine, 59, 863.

BERGLAND, R.M., RAY, B.S. \& TORACK, R.M. (1968) Anatomical variations in the pituitary gland and adjacent structures in 225 human autopsy cases. Journal of Neurosurgery, 28, 93.
Berke, J.P., Buxton, L.F. \& Kokmen, E. (1975) The 'empty' sella. Neurology, 25, 1137.

Bernasconi, V., Giovanelli, M.A. \& PaPo, I. (1972) Primary empty sella. Journal of Neurosurgery, 36, 157.

Brisman, R., Hughes, J.O. \& Holub, D.A. (1972) Endocrine function in nineteen patients with empty sella syndrome. Journal of Clinical Endocrinology and Metabolism, 34, 570.

Bryner, J.R. \& Greenblatt, R.B. (1977) Primary empty sella syndrome with elevated serum prolactin. Obstetrics and Gynecology, 50, 375.

Cupps, T.R. \& Woolf, P.D. (1978) Primary empty sella syndrome with panhypopituitarism, diabetes insipidus and visual field defects. Acta endocrinologica, 89, 445.

Faglia, G., Beck-Peccoz, P., Ambrosi, B., Ferrari, C. \& Giovanni, M. (1973) The empty sella syndrome. Lancet, i, 149.

Ganguly, A., Stanchfield, J.B., Roberts, T.S., West, C.D. \& TYLER, F.H. (1976) Cushing's syndrome in a patient with an empty sella turcica and a microadenoma of the adenohypophysis. American Journal of Medicine, 60, 306.

Jordan, R.M., Kendall, J.W. \& Kerber, C.W. (1977) The primary empty sella syndrome. Analysis of the clinical characteristics, radiographic features, pituitary function and cerebrospinal fluid adenohypophysial hormone concentrations. American Journal of Medicine, 62, 569.

Marisson, R. \& Pimstone, B. (1973) Diabetes insipidus associated with an empty sella. Postgraduate Medical Journal, 49, 274.

Molitch, M.E., Hieshima, G.B., Marcovitz, S., Jackson, I.M.D. \& WolPERT, S. (1977) Coexisting primary empty sella syndrome and acromegaly. Clinical Endocrinology, 7, 261.

Mortara, R. \& Norrell, H. (1970) Consequences of a deficient sellar diaphragm. Journal of Neurosurgery, 32, 565.

Neelon, F.A., Goree, J.A. \& Lebovitz, H.E. (1973) The primary empty sella. Clinical and radiographic characteristics and endocrine function. Medicine. Baltimore, 52, 73.

Schaison, G. \& Metzger, J. (1969) The primary empty sella: an endocrine study on 12 cases. Acta endocrinologica, 60, 112.

Weisberg, L.A., Zimmerman, E.A. \& Frantz, A.G. (1976) Diagnosis and evaluation of patients with an enlarged sella turcica. American Journal of Medicine, 61, 590. 